\title{
Analysis of blood transfusion predictors in patients undergoing elective oesophagectomy for cancer
}

\author{
Abraham A Ayantunde*, Ming Y Ng, Saurov Pal, Neil T Welch and \\ Simon L Parsons
}

Address: Department of Surgery, Nottingham City Hospital, Hucknall Road, Nottingham NG5 1PB, UK

Email: Abraham A Ayantunde* - biodunayantunde@yahoo.co.uk; Ming Y Ng - m1n9yen@yahoo.com; Saurov Pal - drspal@doctors.org.uk; Neil TWelch - neil.welch@nuh.nhs.uk; Simon L Parsons - simon.parsons@nuh.nhs.uk

* Corresponding author

Published: 25 January 2008

BMC Surgery 2008, 8:3 doi:10.1 I86/147|-2482-8-3
Received: 21 February 2007

Accepted: 25 January 2008

This article is available from: http://www.biomedcentral.com/I47|-2482/8/3

(C) 2008 Ayantunde et al; licensee BioMed Central Ltd.

This is an Open Access article distributed under the terms of the Creative Commons Attribution License (http://creativecommons.org/licenses/by/2.0), which permits unrestricted use, distribution, and reproduction in any medium, provided the original work is properly cited.

\begin{abstract}
Background: Oesophagectomy for cancers is a major operation with significant blood loss and usage. Concerns exist about the side effects of blood transfusion, cost and availability of donated blood. We are not aware of any previous study that has evaluated predictive factors for perioperative blood transfusion in patients undergoing elective oesophagectomy for cancer.

This study aimed to audit the pattern of blood crossmatch and to evaluate factors predictive of transfusion requirements in oesophagectomy patients.

Methods: Data was collected from the database of all patients who underwent oesophagectomy for cancer over a 2-year period. Clinico-pathological data collected included patients demographics, clinical factors, tumour histopathological data, preoperative and discharge haemoglobin levels, total blood loss, number of units of blood crossmatched pre-, intra- and postoperatively, number of blood units transfused, crossmatched units reused for another patient and number of blood units wasted.

Clinico-pathological variables were evaluated and logistic regression analysis was performed to determine which factors were predictive of blood transfusion.

Results: A total of I 45 patients with a male to female ratio of 2.5:I and median age of 68 (40-85) years were audited. The mean preoperative haemoglobin $(\mathrm{Hb})$ was $13.0 \mathrm{~g} / \mathrm{dl}$. $37 \%$ of males $(\mathrm{Hb}<13.0 \mathrm{~g} / \mathrm{dl})$ and $29 \%$ of females $(\mathrm{Hb}<1 \mathrm{I} .5 \mathrm{~g} / \mathrm{dl})$ were anaemic preoperatively. A total of $124 \mathrm{I}$ blood units were crossmatched and 316 units were transfused to $7 /$ patients. Seventy four patients $(5 \mathrm{l} \%)$ did not require blood transfusion during their hospital episode. 846 blood units not used for oesophagectomy patients were reused for other patients and 79 units were wasted. The overall crossmatch to transfusion ratio was 4:I and reuse and wastage rates were $65.2 \%$ and $6.3 \%$ respectively. The independent predictors of blood transfusion include age $>70$ years, $\mathrm{Hb}$ level $<1 \mathrm{l} .0 \mathrm{~g} / \mathrm{dl}$, T-stage, presence of postoperative complications and anastomotic leak.

Conclusion: The cohort of patients audited was over-crossmatched. The identified independent predictors of blood transfusion should be considered in preoperative blood ordering for oesophagectomy patients. This study has directly led to a reduction in the maximum surgical blood-ordering schedule for oesophagectomy to 2 units and a reaudit is underway.
\end{abstract}




\section{Background}

Oesophageal cancer is the eighth leading cancer and the sixth leading cause of death from cancer worldwide. The prognosis for oesophageal cancer is poor and there has been an alarming rise in the incidence [1-3]. Anaemia is the most frequently observed haematological abnormality in cancer patients and occurs in about 30\% of patients with oesophagogastric cancers (OGC) [4]. Our experience in Nottingham has shown that up to two-third of our patients presented with some degree of anaemia at the diagnosis of their cancer. We were able to demonstrate in a recent pilot study that more than half of newly diagnosed patients with gastric or oesophageal cancers were iron deficient [5].

Cancer-related anaemia is usually caused by multiple factors. The disease itself through blood loss and poor dietary intake due to dysphagia, anorexia and vomiting can cause anaemia in patients with cancer. Anaemia of chronic disease specific to cancer patients is believed to be due to activation of the immune and inflammatory pathways leading to release of cytokines [6,7]. It can also be exacerbated by side effects of treatment such as cytotoxic chemotherapy as a result of myelosuppression, suppression of erythropoietin production and/or a reduction in bone marrow response to erythropoietin [6]. Most patients with oesophagogastric cancers require operation to remove their cancer and this involves further blood loss. Sutton et al [8] have previously shown that oesophagectomy with extensive lymphadenectomy are usually accompanied by blood transfusion more commonly than radical operations for other gastrointestinal cancers. Anaemia can compound and delay recovery from such surgical procedure and the presence of anaemia prior to operation is associated with increase complication rates and transfusion requirements [9].

Blood transfusion is a rapid method of correcting anaemia and currently one of the common forms of treatment offered to cancer patients. However, concerns have been raised about the side effects of transfusion, cost and availability of donated blood [10]. The indications and trigger for blood transfusion have been redefined in the last decade so as to ensure that blood and blood products are considered and treated as medications in their own merit [11]. There is evidence that perioperative blood transfusion has immunomodulatory effect and adversely affects outcome in patients undergoing oesophagectomy for cancer [12]. We are not aware of any previous study that has evaluated predictive factors for perioperative blood transfusion in patients undergoing elective oesophagectomy for cancer.

This study aimed to audit the pattern of blood crossmatch and transfusion requirements in patients undergoing oesophagectomy for cancer. We evaluated the reuse and wastage rates of the blood primarily crossmatched for oesophagectomy patients and identified possible factors predictive of perioperative blood transfusion in our cohort of patients.

\section{Methods}

Data was retrospectively collected from a database of all patients who underwent elective oesophagectomy for cancer at our institution between January 2003 and December 2004. The approval for this study was granted by the Nottingham City Hospital Audit and Clinical Governance Department. Operative procedures were carried out through a two-phase approach for oesophagectomy and a two-field lymphadenectomy. Clinico-pathological and laboratory data for these patients was obtained from our unit, the Hospital Information Support System (HISS), the blood bank databases and Patient Administration System (PAS). Clinico-pathological data collected included patients demographics, clinical factors, tumour histopathological data, preoperative and discharge haemoglobin levels, operative blood loss, number of units of blood crossmatched pre-, intra- and post-operatively, number of blood units transfused, crossmatched units reused for another patient and number of blood units wasted.

This audit covered the period when the recommended routine preoperative crossmatching by our Oesophagogastric unit for oesophagectomy was 4-6 units. Anaemia was defined on the basis of haemoglobin levels below the lower limit of normal for our laboratory reference values in accordance with the World Health Organization (WHO) criteria [13] with $\mathrm{Hb}<13.0 \mathrm{~g} / \mathrm{dl}$ in males and $<11.5 \mathrm{~g} / \mathrm{dl}$ in females. Total blood loss was calculated as the sum of intraoperative blood measured by the anaesthesiologist according to the contents of the suction bottles \& the weight change of surgical swabs and postoperative blood loss. The criteria used as guidelines for blood transfusion in our unit during the audited period included significant blood loss $>800 \mathrm{ml}$, haemodynamic instability or persistent postoperative haemoglobin $<8.0 \mathrm{~g} / \mathrm{dl}$. The total blood loss and transfusion requirements were compared between anaemic and non-anaemic patient groups. We then evaluated the effect of various clinico-pathological factors on blood transfusion requirements.

\section{Statistical analysis}

Statistical analysis was performed using the SPSS version 13.0 for windows-software (SPSS, Chicago, Illinois, USA) to present descriptive statistics. The mean and median values were calculated for continuous and discrete variables respectively. Univariate and multivariate analyses were performed to determine the risk factors for blood transfu- 
sion. Statistical significance was tested using Mann-Whitney U-test or student t-test where appropriate. Variables that demonstrated a significant relationship on univariate analysis were included in a multiple stepwise logistic regression analysis to identify the significant independent predictors of blood transfusion. The level of significance was set at p-value less than 0.05 .

\section{Results}

A total of 145 consecutive patients were included in the study with 104 males and 41 females (Male: Female ratio of 2.5:1). The median age was $68(40-85)$ years. The predominant histological type was adenocarcinoma (107) compared with squamous cell carcinoma (38). The mean pre-operative haemoglobin (Hb) was $13.0(9-17.5) \mathrm{g} / \mathrm{dl}$. Of the male group, 39 patients $(37.5 \%)$ were anaemic preoperatively $(\mathrm{Hb}<13.0 \mathrm{~g} / \mathrm{dl})$ and 12 patients $(29.7 \%)$ of the female group were anaemic preoperatively $(\mathrm{Hb}<11.5$ $\mathrm{g} / \mathrm{dl}$ ). There was no difference in the distribution of comorbid factors between the anaemic and non-anaemic groups. The mean discharge Hb was 11.0 (7.9 - 15.6) g/ $\mathrm{dl}$. The median operative blood loss was $700 \mathrm{ml}(150-$ 2400 ) with a mean of $849 \mathrm{ml}$ and there was no significant difference between the anaemic and non-anaemic patients $(p=0.343)$. Forty-four percent of the patients had neoadjuvant chemotherapy and there was no significant difference in operative blood loss between this group and those who did not receive neoadjuvant chemotherapy.

A total of 1241 blood units were crossmatched and 74\% were performed preoperatively, 3\% between intra-operative period to 48 hours postoperatively and $23 \%$ from 48 hours postoperatively to discharge. The median number of blood units crossmatched from the preoperative period to discharge was $6(0-34)$ units with a mean of 8.6 units. The median number of blood units crossmatched preoperatively was $6(0-23)$ units with a mean of 6.3 units. The median number of blood units crossmatched from the start of the operation to 48 hours postoperatively was 0 ( 0
- 7) units with a mean of 0.3 unit. The median number of blood units crossmatched from 48 hours postoperatively to discharge was $0(0-30)$ units with a mean of 2.0 units. Thirty-nine percent of the patients had multiple peri-operative blood crossmatch over the upper limit of 6 units that was routinely performed during the audited period and the reasons are outlined in Table 1.

Forty-nine percent $(71 / 145)$ of the patients were transfused with a total of 316 blood units. Ninety-six percent of the transfusions occurred between intraoperative period and discharge (Figure 1). The median number of blood transfused was $4(1-18)$ units with a mean of 4.5 units in this group of patients. Median operative blood loss was higher in patients who were transfused than those that were not transfused but the difference did not reach a statistical significance ( $\mathrm{p}$-value $=0.168$ ). The risk factors for perioperative blood transfusion on univariate analysis are shown in Table 2. The independent predictors of blood transfusion are age more than 70 years, $\mathrm{Hb}$ level less than $11.0 \mathrm{~g} / \mathrm{dl}$, T-stage, presence of perioperative complications and anastomotic leak (Table 3). There was no difference between the two groups in relation to gender, tumour location, histology, differentiation, and lymph node involvement. A direct correlation between the severity of preoperative anaemia and perioperative blood transfusion requirements was observed in spite of similar operative blood loss in the two groups ( $\mathrm{p}=0.013$ ).

A total of 846 blood units that were crossmatched primarily for oesophagectomy patients were reused for another group of patients and 79 blood units were wasted overall. The overall crossmatch to transfusion ratio $(\mathrm{C} / \mathrm{T}$ ratio) was $4: 1$ with overall reuse and wastage rates of $65.2 \%$ and $6.3 \%$ respectively. C/T ratio was significantly higher in patients who had six or less number of blood units crossmatched compared with patients with more than six units crossmatched $(\mathrm{C} / \mathrm{T}$ ratio $8.5: 1$ versus $2.8: 1 ; \mathrm{p}=0.001$ ).

Table I: Reasons for multiple blood ordering of more than six units in 56 patients

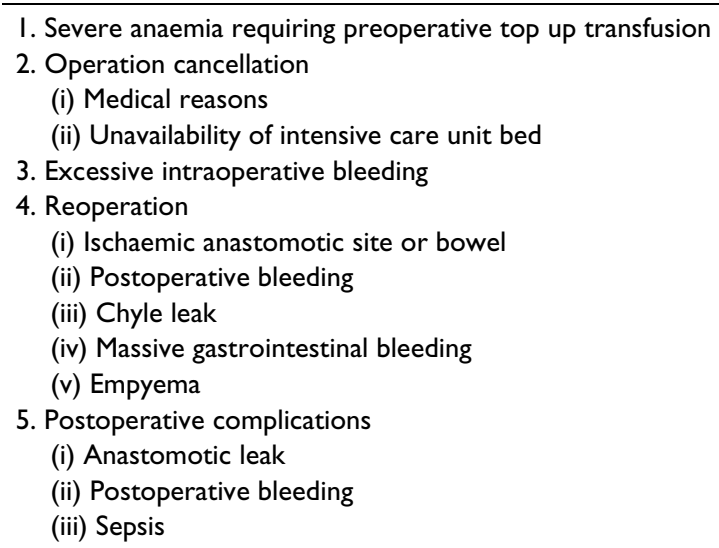




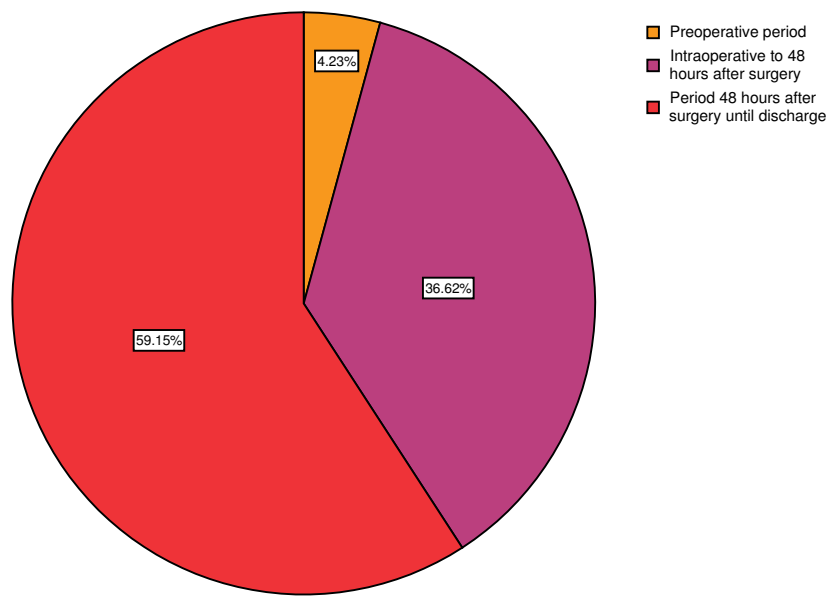

Figure I

Pie chart showing the time period of perioperative blood transfusion in patients undergoing oesophagectomy.

The wastage rate was twice as high in the former compared with the latter patient groups (9\% versus $4.5 \%$ ).

\section{Discussion}

Surgery is still the main treatment option for oesophageal cancer and recent advances in surgical and anaesthetic techniques with improvements in postoperative care have reduced the risks of oesophageal resection to an acceptable level. It has been reported that oesophagectomy with extensive lymphadenectomy is usually accompanied by blood transfusion more commonly than radical operations for other gastrointestinal cancers $[8,12]$. It is therefore customary that patients planned for oesophagectomy for cancer are routinely grouped and crossmatched so as to ensure that blood is readily available during and immediately after the operation. There have been several studies in the last three decades reviewing blood ordering and transfusion practices on account of gross over ordering of blood much in excess of actual or anticipated needs [1417]. These studies resulted from increasing demand for blood and blood products together with rising costs and increased public and medical concerns regarding transfusion-associated infections and immunosuppression.
Surgical indications have been shown to account for more than half of red cells blood transfusion in the United States [18]. However, it is known that many units of blood routinely ordered for surgery are never utilised, resulting in extra workload for laboratory staff and expenses for the blood banks [15-17]. Such blood units are held in reserve and therefore not immediately available for other patients, which can lead to loss of shelf life and eventual wastage. The cost of blood transfusions to the National Health Service (NHS) in 2000/2001 was estimated to be $£ 898$ millions, representing a $256 \%$ increase since $1994 /$ 1995 in the UK [19]. The demand for blood and blood products has been predicted to increase by $4.9 \%$ by 2008 [20]. The increasing demand for blood, increase in ageing population, possible fall in the donor pool and introduction of further screening tests for donated blood will lead to scarcity and further increase in the costs of blood transfusion $[19,20]$.

This is the first study to the best of our knowledge that evaluated predictive clinico-pathological factors for blood transfusion in patients undergoing elective oesophagectomy for cancer. Four to six units of blood were routinely crossmatched preoperatively for patients undergoing oesophagectomy for cancer at the time covered by this audit in our unit. Significant number of our patients had preoperative anaemia. Our median operative blood loss of $700 \mathrm{ml}$ and transfusion rate are comparable to those reported in the literature [12]. There was no statistically significant difference between the operative blood loss between the anaemic and non-anaemic patients. Patients who were older than 70 years had significantly more tendency for perioperative blood transfusion and we believe this may be related to the presence of more co-morbid factors in them than the younger patients. The younger patients understandably may also have more appropriate physiological compensatory mechanisms to blood loss than the older group.

Our results showed that the number of blood units crossmatched significantly exceeded that which was actually transfused to the patients. Forty-nine percent of our patients were transfused with a mean of 4.5 units and only a third of these patients had more than five units of blood transfused. This finding supports previous reports point-

Table 3: Independent predictors of blood transfusion by logistic regression analysis

\begin{tabular}{|c|c|c|c|}
\hline Factor & p-value & $\mathbf{R R}$ & $95 \%$ Confidence Interval \\
\hline Age $>70$ years & 0.044 & 2.328 & $1.022-5.304$ \\
\hline Hb level <l $1.0 \mathrm{~g} / \mathrm{dl}$ & 0.0001 & 3.225 & $1.797-5.786$ \\
\hline T-stage & 0.004 & 2.436 & I.249- 5.762 \\
\hline Perioperative complications & 0.015 & 2.801 & $1.219-6.436$ \\
\hline Anastomotic leak & 0.028 & 14.545 & $1.33 \mid-158.903$ \\
\hline
\end{tabular}

RR, Relative risk 
Table 2: Risk factors for perioperative blood transfusion in 145 patients undergoing oesophagectomy

\begin{tabular}{|c|c|c|c|}
\hline Factors & Transfused (7I) & Not transfused (74) & P-value \\
\hline Sex: & & & 0.148 \\
\hline Male & 47 & 57 & \\
\hline Female & 24 & 17 & \\
\hline Age: & & & 0.0001 \\
\hline$<70$ years & 31 & 54 & \\
\hline$>70$ years & 40 & 20 & \\
\hline Comorbid factors: & & & 0.002 \\
\hline Yes & 45 & 28 & \\
\hline No & 26 & 46 & \\
\hline ASA Class: & & & 0.004 \\
\hline 1 & 8 & 18 & \\
\hline 2 & 44 & 48 & \\
\hline 3 & 19 & 8 & \\
\hline ECOG score: & & & 0.005 \\
\hline 0 & 27 & 45 & \\
\hline I & 31 & 23 & \\
\hline 2 & 10 & 4 & \\
\hline 3 & 3 & 2 & \\
\hline Haemoglobin levels: & & & 0.001 \\
\hline$<11.0 \mathrm{~g} / \mathrm{dl}$ & 15 & 2 & \\
\hline$\geq 11.0 \mathrm{~g} / \mathrm{dl}$ & 56 & 72 & \\
\hline Tumour site: & & & 0.836 \\
\hline Upper third & I & I & \\
\hline Middle third & 8 & 6 & \\
\hline Lower third & 18 & 16 & \\
\hline GOJ & 44 & 51 & \\
\hline Neoadjuvant chemotherapy: & & & 0.266 \\
\hline Yes & 28 & 36 & \\
\hline No & 43 & 38 & \\
\hline Tumour histology: & & & 0.200 \\
\hline SCC & 22 & 16 & \\
\hline ADC & 49 & 58 & \\
\hline Tumour grade: & & & 0.870 \\
\hline Well & 12 & 13 & \\
\hline Moderately & 26 & 25 & \\
\hline Poorly & 33 & 36 & \\
\hline T-stage: & & & 0.002 \\
\hline I & 5 & 16 & \\
\hline 2 & 9 & 16 & \\
\hline 3 & 55 & 42 & \\
\hline 4 & 2 & 0 & \\
\hline N-stage: & & & 0.166 \\
\hline No & 34 & 27 & \\
\hline NI & 37 & 47 & \\
\hline Operative blood loss: & & & 0.715 \\
\hline$<800 \mathrm{ml}$ & 43 & 47 & \\
\hline$>800 \mathrm{ml}$ & 28 & 27 & \\
\hline Postoperative complications: & & & 0.0001 \\
\hline Yes & 46 & 25 & \\
\hline No & 25 & 49 & \\
\hline Anastomotic leak: & & & 0.001 \\
\hline Yes & 13 & I & \\
\hline No & 58 & 73 & \\
\hline
\end{tabular}

ECOG, Eastern Cooperative Oncology Group; GOJ, Gastro-oesophageal junction;

SCC, Squamous cell carcinoma; ADC, Adenocarcinoma 
ing to the tendency to over crossmatching of blood for patients undergoing major operations [15-17]. The British Committee for Standards in Haematology (BCSH) formulated guidelines stating that, in general, the ratio of the number of blood units ordered and transfused should not normally exceed 2:1 [21]. The overall crossmacth to transfusion ratio was twice the recommended value by the BCSH and in fact fifty-two percent of the transfused patients in this study had blood crossmatched to transfusion ratio above 2:1. This evidently showed that the cohort of patients audited was over-crossmatched and this study has directly led to a reduction in the maximum surgical blood ordering schedule (MSBOS) for oesophagectomy to 2 units. Palmer et al [17] have previously reported that a patient-specific blood ordering system (PSBOS) is more accurate in predicting potential perioperative blood transfusion. Sixty-eight percent of the unused blood primarily crossmatched for our oesophagectomy patients were subsequently reused for other patients but still, $6.3 \%$ of blood units were wasted. This wastage rate falls within the reported rates by previous authors $[22,23]$. A significant proportion of the wastage in this study was due to expiration of the shelf life of blood units.

The adoption of PSBOS approach has the potential and capacity to reduce the workload in the transfusion laboratories, reduce cost, conserve already scarce blood resources and prevent unnecessary blood transfusion and wastage. The rational way to minimize blood wastage and reduce the crossmatch to transfusion ratio is by more precisely predicting and estimating an individual patient's likelihood of requiring transfusion perioperatively. We have evaluated and identified some independent factors that are predictive of patients' likelihood of blood transfusion requirements such as age above 70 years, preoperative haemoglobin less than $11.0 \mathrm{~g} / \mathrm{dl}$, locally advanced tumour, the presence of perioperative complications especially postoperative sepsis and anastomotic leak. The results of this audit support other previous studies $[15,16,21,24,25]$. The current study demonstrated no relationship between the need for blood transfusion and gender, tumour site, histology, differentiation, nodal involvement and the use of neoadjuvant chemotherapy.

The local Hospital Transfusion Committee (HTC) may be able to monitor the effectiveness of the blood requesting policy using the crossmatch to transfusion ratio. Preoperative strategies should incorporate blood ordering services aimed at reducing over crossmatch and avoid wastage of a scarce resource. Greater precision in crossmatch to transfusion ratio can be further improved by careful estimation of an individual patient's likelihood of having blood transfusion perioperatively through the application of identified clinico-pathological and operative risk factors. This approach is likely to address the issues of demand versus supply under the current circumstances of concerns relating to the costs, safety of blood and blood products. Improvements and advances in surgical and anaesthetic techniques with better perioperative care may therefore mean that fewer patients are requiring blood transfusion following their operation.

Thirty-nine percent of our patients had multiple perioperative blood crossmatch whereby there were several instances when blood sample was sent for one or more units of blood to be crossmatched. The reasons for this practice included operation cancellations, severe preoperative anaemia necessitating transfusion before surgery and perioperative complications. Complications leading to multiple blood crossmatch and transfusions were anastomotic leakage, sepsis, reoperation for various reasons and postoperative bleeding. The crossmatch to transfusion ratio was significantly lower (C/T ratio 2.8:1 versus $8.5: 1$ ) and wastage rates was half ( $4.5 \%$ versus $9 \%$ ) in patients who had multiple crossmatch compared with those with six or less units of blood crossmatched. We do agree with Palmer et al [17] that an individual patient-specific blood ordering system may be more accurate in reducing unnecessary crossmatch than the maximal surgical blood ordering system. PSBOS can only be effectively applied by predicting the likelihood of an individual patient risk of receiving blood transfusion in the course of their hospital episode for elective operations. Varney and Guest [19] in an economic study of the annual cost of blood transfusions in the UK for 2000/2001 estimated that the average cost of an adult transfusion of a unit of red blood cells to the NHS was $£ 635$. The estimated cost of a unit of red blood cells including the laboratory services in our hospital is $£ 132$ and this, when calculated for 79 units of blood wasted in this audit will translate into a total of $£ 10,428$.

\section{Conclusion}

The cohort of patients audited in this study was overcrossmatched. The future trends are likely to be related to major changes in the blood ordering and transfusion practice as a result of effect of demand versus supply, evolving surgical and anaesthetic techniques, redefinition of more objective transfusion triggers, availability of possibly cheaper alternatives to blood and blood products and the public's and clinicians' perceptions of safety of blood transfusion. The rising costs of blood transfusion and potential reduction in donor pool make it imperative for us to continue to utilise the scarce blood resources more effectively. The identified independent predictors of blood transfusion should be considered in preoperative blood ordering for patients undergoing oesophagectomy.

\section{Abbreviations}

ADC, Adenocarcinoma; BCSH, British Committee for Standards in Haematology; C/T ratio, Crossmatch to 
transfusion ratio; ECOG, Eastern Cooperative Oncology Group; GOJ, Gastro-oesopjageal junction; Hb, Haemoglobin; HISS, Hospital Information Support System; HTC, Hospital Transfusion Committee; MSBOS, Maximum Surgical Blood Ordering Schedule; NHS, National Health Service; OGC, Oesophagogastric cancer; PAS, Patient Administration System; PSBOS, Patient-Specific Blood Ordering System; SCC, Squamous cell carcinoma; SPSS, Statistical Package for Social Science; WHO, World Health Organization;

\section{Competing interests}

The author(s) declare that they have no competing interests.

\section{Authors' contributions}

AAA participated in the conception, design, acquisition of the data, statistical analysis of the data, interpretation of the data, drafting of the manuscript, critical revision of the manuscript and supervision.

MYN participated in the conception, design, acquisition of the data, interpretation of the data and critical revision of the manuscript.

SP participated in the conception, design, acquisition of the data interpretation of the data and critical revision of the manuscript.

NTW participated in the conception, design, acquisition of the data, statistical analysis of the data, interpretation of the data, drafting of the manuscript, critical revision of the manuscript and supervision.

SLP participated in the conception, design, acquisition of the data, statistical analysis of the data, interpretation of the data, drafting of the manuscript, critical revision of the manuscript and supervision.

\section{All authors read and approved the final manuscript.}

\section{References}

I. Siewert JR, Stein HJ: Classification of adenocarcinoma of the oesophagastric junction. Br J Surg 1998, 85: I 457-I 459 .

2. Siewert JR, Feith M, Werner M, Stein HJ: Adenocarcinoma of the oedophagogastric junction: Results of surgical therapy based onanatomic/topographic classification in 1002 consecutive patients. Ann Surg 2000, 232(3):253-36I.

3. Robert T, Murray T, Bolden S: Cancer statistics 2000. CA Cancer J Clin 2000, 50:7-33.

4. Mano M, Butzberger P, Reid A, Rodger A, Soutar R, Welsh J: Current role of erythropoietin in the management of patients with haematological and solid malignancies. Cancer Therapy 2005, 3:4I-56.

5. Ayantunde AA, Welch NT, Parsons SL: Measures of body iron stores and iron deficiency anaemia in patients with oesophagogastric cancers. Hepato-Pancreato-Biliary (HPB) Journal 2006, 8(Supplement): 192 .

6. Bron D, Meuleman N, Mascaux C: Biological basis of anaemia. Semin Oncol 200I, 28(Suppl 8): I-6.
7. Kurzrock R: The role of cytokines in cancer related fatigue. Cancer 200I, 92: I684-I688.

8. Sutton DN, Wayman J, Griffin SM: Learning curve for oesophageal cancer surgery. BrJ Surg 1998, 85:1399-1402.

9. Dunne JR, Malone D, Tracy JK, Gannon C, Napolitano LM: Perioperative anaemia: an independent risk factor for infection, mortality, and resource utilization in surgery. The Journal of surgical research 2002, 102(2):237-244.

10. Goodnough LT, Brecher ME, Kanter MH, AuBuchon JP: Transfusion medicine. Part I: blood transfusion. N Engl J Med 1999, 340:438-447.

II. Williamson LM, Lowe S, Love EM: Serious hazards of transfusion (SHOT) initiative: analysis of the first two annual reports. BM] 1999, 319:16-19.

12. Dresner SM, Lamb PJ, Shenfine J, Hayes N, Griffin SM: Prognostic significance of peri-operative blood transfusion following radical resection for oesophageal carcinoma. EJSO 2000, 26:492-497.

13. WHO/UNICEF/UNU: Iron deficiency anaemia: assessment, prevention and control. 200I [http://www.who.int/entity/nutri tion/publications/en/ida assessment prevention control.pdf]. Geneva, World Health Organisation (WHO/NHD/0I.3). Accessed $10^{\text {th }}$ January 2007

14. Friedman BA, Oberman HA, Chadwick AR, Kingon KI: The maximum surgical blood order schedule and surgical blood use in the United States. Transfusion 1976:380-387.

15. vanKlei WA, Moons KGM, Rheineck-Leyssius AT, Kalkman CJ, Knape JTA, et al.: A reduction in type and screen: preoperative prediction of RBC transfusions in surgery procedures with intermediate transfusion risks. Br J Anaesth 200I, 87:250-257.

16. vanKlei WA, Moons KGM, Rheineck-Leyssius AT, Kalkman C), Rutten CLG, et al.: Validation of a clinical prediction rule to reduce preoperative type and screen procedures. Br J Anaesth 2002, 89:221-225.

17. Palmer T, Wahr JA, Reilly MO, Greenfield MLVH: Reducing unnecessary cross matching: A patient-specific blood ordering system is more accurate in predicting who will receive a blood transfusion than the maximum blood ordering system. Anaesth Analg 2003, 96:369-375.

18. Vamvakas EG, Taswell HF: Long-term survival after blood transfusion. Trasnfusion 1994, 34:47|-477.

19. Varney SJ, Guest JF: The annual cost of blood transfusions in the UK. Transfusion Medicine 2003, 13:205-218.

20. Wells AW, Mounter PJ, Chapman CE, Stainsby D, Wallis JP: Where does blood go? Prospective observational study of red cells transfusion in north England. BMJ 2002, 325:803.

21. The British Committee for Standards in Haematology(BCSH): Guidelines for the use of red cell transfusions. $\mathrm{Br} J$ Haematol 200I, II 3:24-3I

22. Chapman JF, Cook R: The blood stocks management scheme, a partnership venture between the National Blood Service of England and North Wales and participating hospitals for maximizing blood supply chain management. Vox Sanguinis 2002, 83:239-246.

23. James RM, Brown S, Parapia LA, Williams AT: The impact of a I0year audit cycle on blood usage in a district general hospital. Transfusion Medicine 200I, I I:37I-375.

24. Ong AH, Sim KM, Boey SK: Preoperative prediction of intraand postoperative red cell transfusion in surgical patients. Ann Acad Med Singapore 1997, 26:430-434.

25. Keating EM, Meding JB, Faris PM, Ritter MA: Predictors of transfusion risk in elective knee surgery. Clin Orthop 1998:50-90.

\section{Pre-publication history}

The pre-publication history for this paper can be accessed here:

http://www.biomedcentral.com/1471-2482/8/3/prepub 